\title{
Impact of Centrosome Aberrations on Chromosome Segregation and Tissue Architecture in Cancer
}

\author{
ERich A. NigG, ${ }^{1}$ DominiK Schnerch, ${ }^{1,2}$ AND Olivier Ganier ${ }^{1}$ \\ ${ }^{1}$ Biozentrum, University of Basel, Basel $\mathrm{CH}-4056$, Switzerland \\ Correspondence: erich.nigg@unibas.ch
}

\begin{abstract}
Centrosomes determine the disposition of microtubule networks and thereby contribute to regulate cell shape, polarity, and motility, as well as chromosome segregation during cell division. Additionally, centrioles, the core components of centrosomes, are required for the formation of cilia and flagella. Mutations in genes coding for centrosomal and centriolar proteins are responsible for several human diseases, foremost ciliopathies and developmental disorders resulting in small brains (primary microcephaly) or small body size (dwarfism). Moreover, a long-standing postulate implicates numerical and/or structural centrosome aberrations in the etiology of cancer. In this review, we will discuss recent work on the role of centrosome aberrations in the promotion of genome instability and the disruption of tissue architecture, two hallmarks of human cancers. We will emphasize recent studies on the impact of centrosome aberrations on the polarity of epithelial cells cultured in three-dimensional spheroid models. Collectively, the results from these in vitro systems suggest that different types of centrosome aberrations can promote invasive behavior through different pathways. Particularly exciting is recent evidence indicating that centrosome aberrations may trigger the dissemination of potentially metastatic cells through a non-cell-autonomous mechanism.
\end{abstract}

Centrosomes function as major organizers of intracellular microtubule networks in animal cells (Bornens 2012). Hence, they influence cell shape, polarity, and motility. Furthermore, centrosomes contribute to the assembly of the bipolar spindle apparatus during mitosis, with important consequences for chromosome segregation and the positioning of the cleavage furrow. Aberrant centrosome numbers cause the formation of mono- or multipolar spindles, often with dire consequences for the fidelity of chromosome segregation (Nigg 2002; Godinho and Pellman 2014; Gönczy 2015). A typical centrosome comprises two centrioles, embedded in a proteinaceous matrix known as the pericentriolar material (PCM) (Woodruff et al. 2014; Conduit et al. 2015). Centrioles are cylindrical organelles built of exceptionally stable microtubules, and they display an evolutionarily conserved ninefold rotational symmetry (Azimzadeh and Marshall 2010; Gönczy 2012; Guichard et al. 2013). The PCM is a dynamic structure harboring more than 200 distinct proteins, including proteins important for microtubule nucleation (Paz and Luders 2017) and components of signaling pathways (Arquint et al. 2014). Importantly, centrioles are required not only for centrosome assembly but also for the formation of cilia and flagella (Sánchez and Dynlacht 2016). In these latter roles, centrioles are often referred to as basal bodies (Garcia and Reiter 2016). In recent years, mutations in several genes coding for centrosomal proteins or proteins of the basal body ciliary apparatus were shown to cause human diseases, notably ciliopathies and developmental disorders affecting either the brain (primary microcephaly) or the entire body (dwarfism). Accordingly, much research effort is currently devoted to elucidating the pathways that link specific alterations in centrosomal or centriolar proteins to the above disease phenotypes (Nigg and Raff 2009; Bettencourt-Dias et al. 2011; Braun and Hildebrandt 2017).

Researchers also continue to explore purported causal relationships between centrosome aberrations and cancer. In a seminal monograph, published at the beginning of the 20th century, Boveri (1914) had proposed that tumorigenesis might be a consequence of chromosome missegregation, which in turn he attributed to multipolar spindles caused by extra centrosomes. Many studies have since followed up on Boveri's hypothesis, and, to date, the prevalence of centrosome aberrations in both solid and hematologic cancers is firmly established. Although centrosome aberrations generally affect only subpopulations of tumor cells, they can be observed already at early stages of tumorigenesis (Lingle et al. 2002; Pihan et al. 2003; Guo et al. 2007; Chan 2011). Traditionally, centrosome aberrations are classified as either numerical or structural, depending on whether the abnormalities concern centrosome numbers or structures, but, importantly, these aberrations often occur together (Lingle et al. 1998; Pihan et al. 2003; Guo et al. 2007). Although the origins and consequences of numerical aberrations have been studied extensively, research on structural aberrations has barely begun (Nigg 2002; Godinho and Pellman 2014; Gönczy 2015). Genetic evidence implicating centrosomal proteins in the etiology of human cancer remains scarce, but experimentally induced centrosome aberrations are able to trigger tumorigenesis in both Drosophila and mouse models

\footnotetext{
${ }^{2}$ Present address: Department of Medicine I, Medical Center-University of Freiburg, Faculty of Medicine, University of Freiburg, Freiburg 79106 , Germany

(C) 2017 Nigg et al. This article is distributed under the terms of the Creative Commons Attribution License, which permits unrestricted reuse and
} redistribution provided that the original author and source are credited. 
(Basto et al. 2008; Coelho et al. 2015; Serçin et al. 2016; Levine et al. 2017). What remain to be clarified are to what extent centrosome aberrations contribute to tumor formation and/or progression in human patients and through what mechanisms.

\section{THE CENTROSOME DUPLICATION CYCLE AND ITS ABERRATIONS}

Cell cycle research traditionally focuses on DNA replication during $\mathrm{S}$ phase and chromosome segregation during $\mathrm{M}$ phase. However, it is important to bear in mind that this chromosome duplication-segregation cycle is accompanied by a centrosome duplication-segregation cycle, and that preservation of genome integrity during cell proliferation requires coordination between these two cycles (Nigg and Stearns 2011; Firat-Karalar and Stearns 2014; Fu et al. 2015). This coordination is achieved through a number of key regulatory proteins that control both processes (Nigg and Holland 2018). In brief, a typical $\mathrm{G}_{1}$ phase cell harbors a single centrosome, comprising two centrioles. These two centrioles are then duplicated during $\mathrm{S}$ phase, so that by $\mathrm{G}_{2}$, the cell harbors two centrosomes, each comprising a pair of centrioles. By virtue of their association with the poles of the mitotic spindle apparatus, the two centrosomes then segregate during $M$ phase. To keep centriole and centrosome numbers constant in each cell cycle, regulatory mechanisms need to ensure that centriole duplication occurs once and only once, and that only one new centriole is built per preexisting centriole (Nigg 2007). In recent years much has been learned about the regulation of centriole duplication, as well as structural aspects of centriole biogenesis (Fu et al. 2015; Nigg and Holland 2018). For the sake of simplicity, we summarize that centriole biogenesis relies on a core module composed of three crucial centriole duplication factors, Pololike kinase 4 (PLK4), SAS-6, and STIL (Arquint and Nigg 2016). PLK4 functions as the master regulator of centriole biogenesis (Bettencourt-Dias et al. 2005; Habedanck et al. 2005; Kleylein-Sohn et al. 2007; Rodrigues-Martins et al. 2007), SAS-6 represents a core component of a scaffolding structure, termed cartwheel, that imparts the evolutionarily conserved ninefold symmetry to centrioles (Kitagawa et al. 2011; van Breugel et al. 2011; Hirono 2014; Guichard et al. 2017), and STIL plays crucial roles in centriole assembly through interactions with both PLK4 and SAS-6 (Arquint and Nigg 2014; Ohta et al. 2014; Arquint et al. 2015; Kratz et al. 2015; Moyer et al. 2015). Importantly, depletion of PLK4, SAS-6, or STIL stops centriole duplication, and, conversely, overexpression of either protein triggers centrosome amplification (Nigg and Holland 2018).

Because centrosomes are important for continued proliferation of normal (untransformed) mammalian cells, centrosome aberrations are generally deleterious. Thus, experimentally induced loss of centrosomes triggers robust cell cycle arrest in both cultured cells and mouse embryos (Hinchcliffe et al. 2001; Khodjakov and Rieder 2001; Bazzi and Anderson 2014). This arrest can be over- come by inactivation of the p53 pathway, explaining why p53-deficient cancer cells fail to arrest in response to centrosome loss (Bazzi and Anderson 2014; Lambrus et al. 2015; Wong et al. 2015). Recent genome-wide screens have identified a p53-dependent pathway, including the p53-binding protein 53BP1, the deubiquitinase USP38, and the CDK inhibitor $\mathrm{p} 21$, that imposes a proliferation arrest on centrosome-deficient cells (Fong et al. 2016; Lambrus et al. 2016; Meitinger et al. 2016). Most likely, this newly discovered pathway detects the extended mitotic duration that is caused by the absence of centrosomes, leading to its designation as "mitotic surveillance pathway" (Lambrus and Holland 2017). In future, it will be interesting to elucidate the exact contributions of this pathway to normal physiology and disease.

Cells respond not only to loss of centrosomes but also to extra centrosomes. Accordingly, centrosome amplification also suppresses cell proliferation and, again, the arrest depends on p53 (Holland et al. 2012; Levine et al. 2017). Importantly, however, the response to centrosome amplification does not require USP28 or 53BP1, demonstrating that centrosome loss and centrosome amplification activate distinct pathways. How cells detect extra centrosomes and how they respond to this anomaly remains to be fully understood, but a recent study identifies the PIDDosome, a multiprotein complex responsible for caspase-2 activation, as a key component of the pathway (Fava et al. 2017). PIDDosome components were found to colocalize with mature centrioles, suggesting that proximity-induced activation stimulates caspase-2, which then results in caspase2-mediated MDM2 cleavage, p53 stabilization, and p21dependent cell cycle arrest (Fava et al. 2017). It has also been reported that extra centrosomes trigger p53 stabilization through the kinase LATS2 (Ganem et al. 2014), and it appears safe to predict that additional components linking centrosome amplification to p53 activation await discovery.

\section{IMPACT OF CENTROSOME ABERRATIONS ON FIDELITY OF CHROMOSOME SEGREGATION}

Although centrosomes play a major role in bipolar spindle formation and chromosome segregation in somatic human cells, centrosomes are not required for spindle formation in all organisms or cell types (Szollosi et al. 1972; Basto et al. 2006; Bornens 2012). This is illustrated best by higher land plants or oocytes of many animal species, which form bipolar spindles even though they lack centrosomes. Similarly, cell division occurs in the absence of centrosomes in planarians, where centrioles are only assembled in terminally differentiated multiciliated cells (Azimzadeh et al. 2012). Research on the mechanisms underlying centrosome-independent spindle formation has revealed that these rely on microtubule nucleation in the vicinity of chromatin and involve the small GTPase Ran as well as several microtubule-binding proteins and microtubule-dependent motor proteins (Prosser and Pelletier 2017). Importantly, centrosome-dependent and cen- 
trosome-independent mechanisms for spindle formation coexist in somatic human cells (Karsenti and Vernos 2001; Khodjakov and Rieder 2001), and this has important implications for the clustering of extra centrosomes in tumor cells (see below).

Although structural centrosome aberrations are thought to reflect the unbalanced expression of PCM components in tumors, most numerical centrosome aberrations are likely to result from centriole overduplication or division failure (Nigg 2002; Godinho and Pellman 2014; Gönczy 2015). A priori, both types of aberrations can lead to the formation of multipolar spindles. Spindle multipolarity often reflects numerical aberrations, but occasionally can arise also through PCM fragmentation (Fig. 1). The two etiologies can readily be distinguished by monitoring of centriolar markers: whereas numerical aberrations will produce multipolar spindles with each pole containing at least one centriole, PCM fragmentation will result in extra spindle poles devoid of centrioles. When multipolarity can be attributed to numerical aberrations, a question of potential clinical importance concerns the origin of these aberrations. If centriole overduplication represents the root cause, any subsequent multipolar division will lead to the segregation of a diploid genome into more than two cells, and the resulting hypodiploid progeny is not generally expected to be viable (Ganem et al. 2009; Silkworth et al. 2009). In contrast, when centrosome amplification resulted from division failure, a subsequent multipolar division will concern a tetraploid cell, implying that two complete diploid sets of chromosomes can be distributed among three or more cells. A priori, this would seem to set the stage for the occasional production of viable, aneuploid cells. Considering that tetraploid intermediates are commonly observed in carcinogenesis, it seems plausible that abnormal divisions of tetraploid cells, induced by centrosome aberrations, may constitute a prominent path to aneuploid progeny (Meraldi et al. 2002; Nigg 2002; Ganem et al. 2007).

Spindle multipolarity does not always lead to multipolar divisions. Instead, as a consequence of centrosome clustering, multipolar spindles often coalesce to bipolar spindles prior to cell division (Nigg 2002; Quintyne et al. 2005). This prominent phenomenon of centrosome clustering in tumor cells almost certainly reflects up-regulation of centrosome-independent spindle assembly pathways (see above). Therefore, inhibition of proteins or mechanisms required for centrosome clustering might constitute an attractive strategy for targeting tumor cells harboring extra centrosomes (Nigg 2002; Ganem et al. 2007; Kwon et al. 2008). Importantly, the ability of tumor cells to cluster extra centrosomes increases not only their viability, but also the frequency of chromosome mis-segregation (Ganem et al. 2009; Silkworth et al. 2009). This is because centrosome clustering enhances the occurrence of socalled merotelic microtubule-kinetochore interactions (i.e., interactions of a single chromosomal kinetochore with microtubules emanating from opposite spindle poles), which then increases the frequency of lagging chromosomes, resulting in aneuploidy (Salmon et al. 2005). Thus, centrosome aberrations are now recognized to constitute a prominent cause of whole chromosome instability in cancer.

\section{IMPACT OF CENTROSOME ABERRATIONS ON TISSUE ARCHITECTURE}

Centrosomes function not only in mitotic spindle formation and chromosome segregation but also in the organization of microtubule networks in interphase cells. This

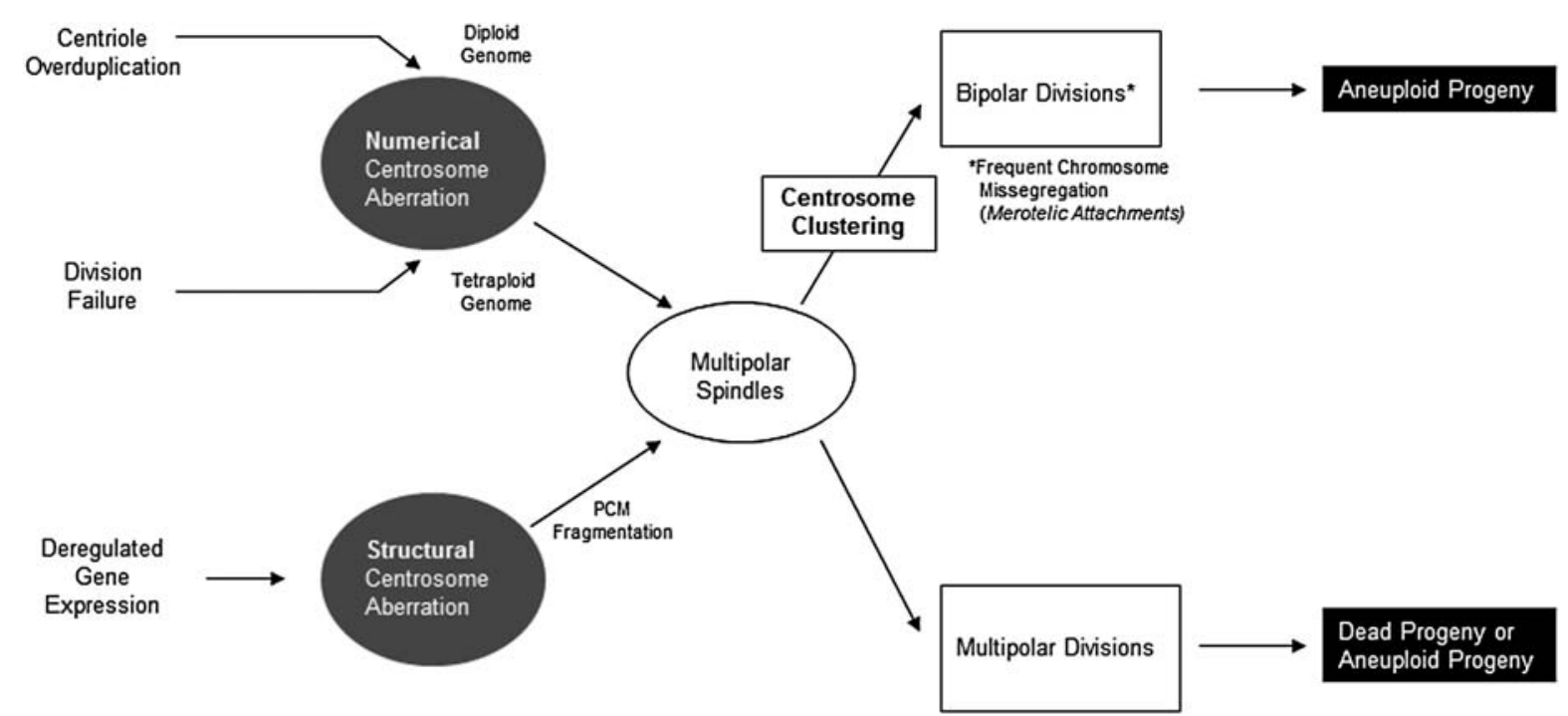

Figure 1. Impact of centrosome aberrations on chromosome segregation. Both numerical and structural aberrations can give rise to multipolar spindles. Multipolar divisions will generally produce dead cells, but centrosome clustering will allow bipolar divisions, albeit at the cost of increased chromosome missegregation. A priori, multipolar divisions are more likely to produce viable progeny if the cells harboring centrosome aberrations carry a tetraploid genome. Hence, the root cause of spindle multipolarity is not irrelevant (Meraldi et al. 2002; Nigg 2002). PCM, pericentriolar material. 
has important consequences for cell shape, polarity, and motility. Thus, centrosome aberrations may influence not only the fidelity of chromosome segregation but also tissue architecture and, potentially, the propensity of tumor cells to metastasize. To explore this possibility, several recent studies used three-dimensional (3D) culture systems to study the impact of centrosome aberrations on the organization of epithelial structures (Godinho et al. 2014; Schnerch and Nigg 2016; Ganier et al. 2017). Collectively, these studies establish that centrosome aberrations profoundly disrupt epithelial architecture. Moreover, they lend support to the hypothesis that centrosome aberrations may contribute to tissue invasion and the dissemination of metastatic cells.

Overexpression of PLK4, the master regulator of centriole duplication, is widely used as the method of choice for inducing numerical centrosome aberrations. Likewise, overexpression of the PCM component Ninein-like protein (NLP) (Casenghi et al. 2003) can be used to explore the impact of structural centrosome aberrations on cell fate (Schnerch and Nigg 2016; Ganier et al. 2017). NLP is frequently overexpressed in human tumors and NLP overexpression in transgenic mice was reported to trigger tumorigenesis (Shao et al. 2010). In the studies described below, effects of centrosome aberrations were studied in 3D spheroids grown in hydrogel matrices (Matrigel) or in 2D monolayer cultures. As summarized in Figure 2, the available evidence suggests that centrosome aberrations can confer invasive properties to epithelial cells through at least three distinct mechanisms, (i) invadopodia formation, (ii) the non-cell-autonomous budding of mitotic cells, and (iii) basal extrusion. In the following, we will briefly describe each of these three mechanisms, and we will highlight methodological and functional differences.

Analysis of human mammary epithelial cells grown in $3 \mathrm{D}$ cultures revealed that centrosome amplification, triggered by overexpression of PLK4, causes the formation of striking invasive protrusions known as invadopodia (Godinho et al. 2014). The observed invasive phenotypes were remarkably similar to those seen upon overexpression of ERBB2, a prominent breast cancer oncogene. Moreover, dissection of the underlying pathway revealed that PLK4induced centrosome amplification resulted in increased centrosomal microtubule nucleation, which then enhanced the activity of the small GTPase Rac1, resulting in the disruption of cell-cell adhesion (Godinho et al. 2014). In full agreement with the original findings, we have subsequently reproduced invadopodia formation in response to numerical centrosome aberrations induced by PLK4 overexpression (Ganier et al. 2017). Remarkably, however, we found that an indistinguishable invasive phenotype could also be triggered by structural centrosome aberrations, as induced by NLP overexpression (Ganier et al. 2017). This suggests that different types of centro-

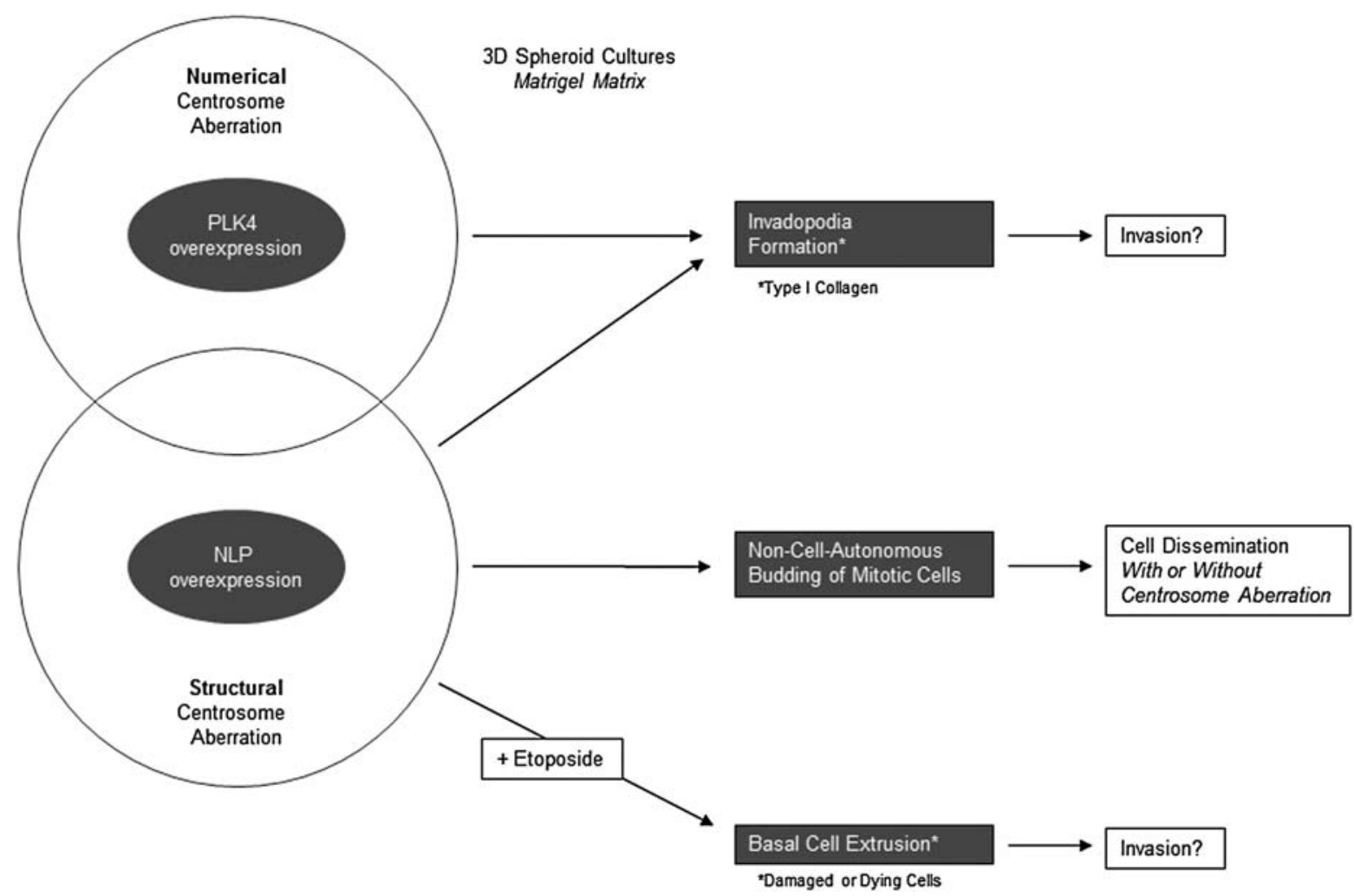

Figure 2. Impact of centrosome aberrations on tissue architecture and invasion. In vitro studies using three-dimensional (3D) spheroid models suggest that centrosome aberrations can confer invasive properties. The schematic distinguishes three distinct mechanisms, invadopodia formation, the non-cell-autonomous budding of mitotic cells, and basal extrusion. PLK4, Polo-like kinase 4; NLP, Nineinlike protein. 
some aberrations can cause alterations in the cytoskeleton that then lead to invadopodia formation. One intriguing methodological aspect of the original study was the use of type I collagen to sensitize invasion assays (Godinho et al. 2014). Type I collagen is known to increase the stiffness of Matrigel matrices, thereby favoring invadopodia formation (Di Martino et al. 2015; Artym 2016). In our laboratory, we found that PLK4- or NLP-induced invadopodia formation was strictly dependent on addition of type I collagen to Matrigel preparations (Schnerch and Nigg 2016; Ganier et al. 2017). This dependence on type I collagen could be interpreted to suggest that invadopodia formation represents a rather subtle phenotype, but we emphasize that type I collagen frequently accumulates within tumor stroma (Artym 2016). Thus, addition of this extracellular matrix component to Matrigel may well mimic a pathophysiologically relevant milieu.

In our laboratory we have recently discovered a novel process, termed "budding," that also offers the potential to contribute to the spreading of metastatic cells (Ganier et al. 2017). This process is mechanistically distinct from invadopodia formation and does not require addition of type I collagen to Matrigel. Specifically, we found that structural centrosome aberrations, induced by overexpression of NLP, promote the dissemination of living cells from epithelial spheroid cultures. Most remarkably, live cell imaging showed that all budding cells were invariably undergoing mitosis. Induction of NLP transgene expression in spheroid cultures caused the formation of structural centrosome aberrations that closely resembled those seen in malignant tumors. Furthermore, just like in tumors, these aberrations were not seen in all cells of a given spheroid. In fact, because the NLP transgene was not expressed in all cells, this resulted in epithelia harboring cells with centrosome aberrations interspersed with cells lacking such aberrations. A high proportion of cells $(>50 \%)$ with structural centrosome aberrations was a prerequisite for cell budding from spheroids, but, remarkably, only half of the disseminating mitotic cells were found to carry such aberrations. This strongly suggests that budding results from multicellular cooperation and represents a non-cell-autonomous phenomenon (Fig. 3). Regarding the mechanisms leading to cell budding, we found that NLP-induced structural centrosome aberrations triggered cytoskeletal reorganizations, resulting in weakened E-cadherin junctions and randomization of spindle orientation. Moreover, cells budding from NLP-overexpressing spheroids showed marked delays in mitotic progression and extensive membrane blebbing. As both mitotic delays and membrane blebbing were previously recognized to reflect pressure induced by confinement (Cattin et al. 2015), we used atomic force microscopy to measure the stiffness of epithelial cells with or without centrosome aberrations. The analysis of epithelial cells at different cell cycle stages revealed that NLPinduced structural centrosome aberrations markedly increased cellular stiffness. In contrast, no major difference in these mechanobiological properties could be detected in response to numerical centrosome aberrations induced by PLK4 (Ganier et al. 2017). These data led us to propose that NLP-induced structural centrosome aberrations trigger the dissemination of mitotic cells from mosaic epithelia, but that the escaping cells do not necessarily have to carry any centrosome aberration (Fig. 3). One attraction of this newly discovered mechanism for cell dissemination is that it may explain a long-standing conundrum in the centrosome field. Considering that centrosome aberrations are expected to impair cell viability, their prominence in aggressive tumors is puzzling. However, it is well recognized that centrosome aberrations are hardly ever present in all cells of a tumor cell population. Thus, a non-cell-autonomous mechanism for cell dissemination offers an explanation for how centrosome aberrations might conceivably promote metastasis, without the invading cells themselves necessarily carrying deleterious centrosome aberrations (Fig. 3).

Removal of damaged or dying cells is critical for the preservation of the barrier function of epithelia. Research into the mechanism underlying this cell extrusion has revealed that cells destined to undergo apoptosis signal to their living neighbors, which then causes actomyosin ring contractility and the delamination of dying cells from the epithelial sheet (Rosenblatt et al. 2001; Gibson and Perrimon 2005; Rodriguez-Boulan and Macara 2014). In wildtype epithelia, most apoptotic cells are squeezed apically into the glandular lumen, and this requires the repositioning of the actomyosin ring from an apical to a basal location. However, a conspicuous change in extrusion directionality toward the basal side has been observed in epithelia carrying oncogenic mutations, and in this case, the repositioning of the actomyosin ring is inhibited (Slattum et al. 2009, 2014; Gu et al. 2015). Considering that apoptosis is blocked in some tumors, this raises the exciting possibility that "basal cell extrusion" could enable disseminating cells to initiate metastasis (Slattum et al. 2009, 2014; Marshall et al. 2011; Slattum and Rosenblatt 2014; Gudipaty et al. 2017). Having observed that about one-third of cells disseminating from spheroids in response to NLP-induced centrosome aberrations stained positively for activated capase-3, a marker of apoptosis, we asked whether the dissemination of some of the dying cells might represent "basal extrusion." To facilitate mechanistic studies, we adopted an assay commonly used to study basal extrusion and treated spheroids harboring NLP-induced centrosome aberrations with the DNA-damaging drug etoposide (Slattum et al. 2014). Analysis of the apoptotic cells disseminating in response to a combination of NLP overexpression and etoposide treatment revealed all the hallmarks of basal extrusion, notably the absence of basal repositioning of the constricting actomyosin ring and sensitivity to agonists of the sphingosine 1 receptor 2 pathway (D Schnerch, O Ganier, and EA Nigg, unpubl.). From these results we conclude that structural centrosome aberrations can sensitize cells to the activation of the basal extrusion pathway. The observed microtubule and actomyosin reorganizations are highly reminiscent of the cytoskeletal rearrangements observed in cells that lack the adenomatous polyposis coli (APC) gene product or express an oncogenic version of APC (Marshall et al. 2011). We conclude, therefore, that structural centrosome aberrations can also contribute to promote basal extrusion of tumor cells (Fig. 2). 

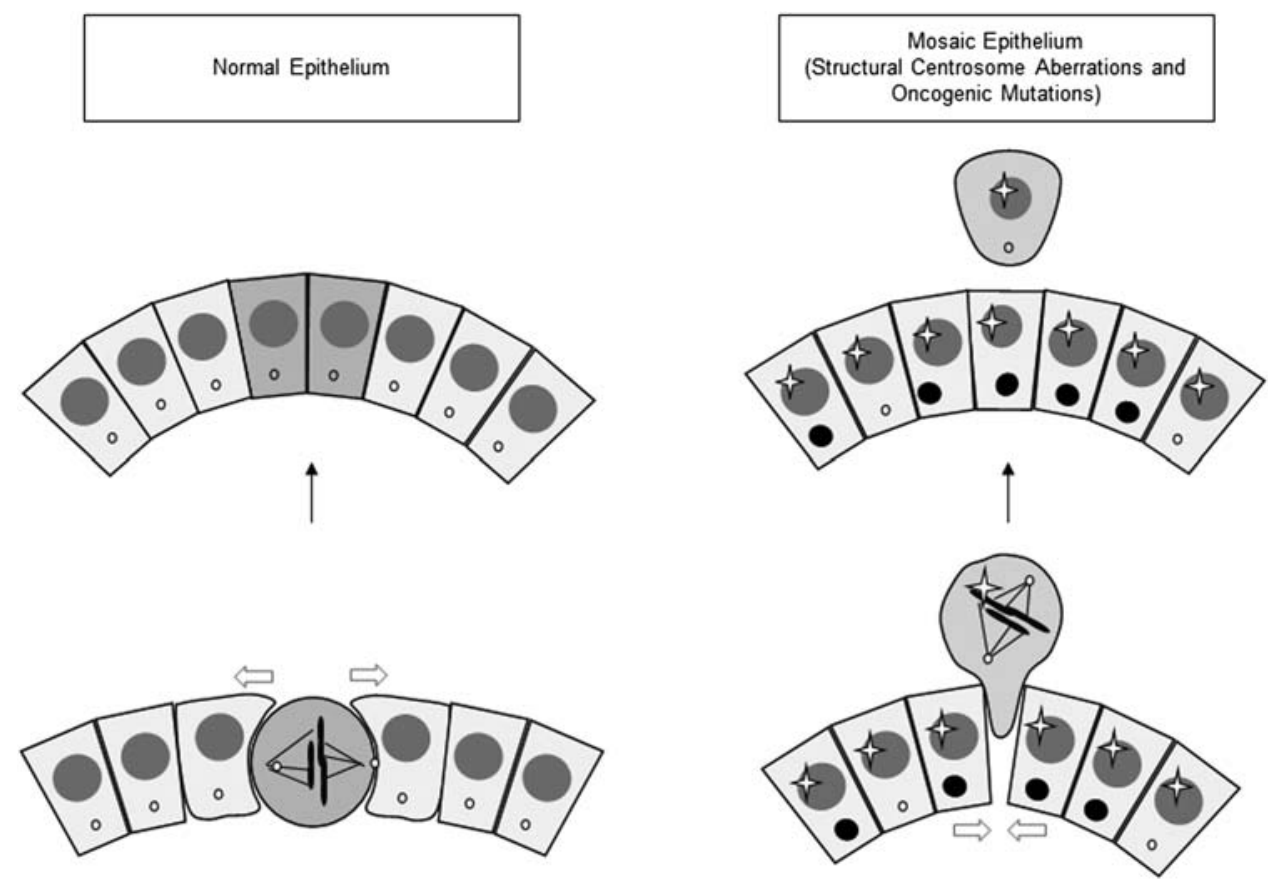

Figure 3. Structural centrosome aberrations cause cell "budding" through non-cell-autonomous mechanism. (Left) When cells divide in a wild-type epithelium, mitotic spindles are positioned in the plane of the sheet and surrounding cells are sufficiently deformable to accommodate the products of cell division. (Right) In a mosaic epithelium comprising cells with and without structural centrosome aberrations, spindle orientation is randomized and surrounding cells show reduced deformability when they harbor structural centrosome aberrations. As a consequence, mitotic cells are occasionally squeezed out of the epithelium through budding, regardless of whether they carry centrosome aberrations. If these cells additionally harbor oncogenic mutations, this proposed non-cell-autonomous process for cell dissemination may promote metastasis. Small open circles, normal centrosomes; large black circles, structurally aberrant centrosomes (due to NLP overexpression); stars, oncogenic mutations. Horizontal arrows refer to forces.

The studies discussed above show that numerical and structural centrosome aberrations cause profound reorganizations of the cytoskeleton and, moreover, exert drastic effects on the polarity of epithelial layers. As a result, cells disseminating from $3 \mathrm{D}$ spheroid structures acquire potentially invasive properties. The available evidence suggests that different types of centrosome aberrations can induce fundamentally different cellular behaviors. In particular, we emphasize that NLP-induced structural centrosome aberrations trigger cell dissemination through a non-cellautonomous mechanism (Ganier et al. 2017). According to our model (Fig. 3), cell dissemination can be triggered in response to centrosome aberrations without the evading cell itself harboring any centrosomal anomalies. Instead, it suffices that neighboring cells carry NLP-induced centrosome aberrations and thereby change the mechanobiological properties of epithelia. This hypothesis has the potential to explain how centrosome aberrations can promote carcinogenesis, even though centrosome aberrations are expected to jeopardize cellular fitness and never affect all cells within a given tumor.

\section{CONCLUSION}

Centrosome aberrations have been implicated in tumorigenesis for more than 100 years. To date, it is firmly established that numerical and structural centrosome aberrations are prominent features of many tumor cells.
Furthermore, experimentally induced centrosome amplification was convincingly shown to trigger tumorigenesis in animals. What remains to be fully understood is the impact of centrosome aberrations on the development and progression of human tumors. Work performed over the past decades supports the notion that centrosome aberrations constitute one prominent root cause of chromosome missegregation. It is now widely accepted that centrosome anomalies likely contribute to explain the aneuploidy and chromosomal instability phenotypes commonly associated with human cancers, vindicating Boveri's early hypothesis. In more recent years, increasing attention is focused on the possibility that centrosome aberrations may disrupt tissue architecture and potentially contribute to confer metastatic properties to cancer cells. One important insight emerging from studies on 2D and $3 \mathrm{D}$ culture models is that different types of centrosome aberrations can trigger mechanistically distinct types of invasive behaviors, including invadopodia formation, the dissemination ("budding") of mitotic cells, and basal extrusion. Although this should caution against premature generalizations, it also offers the exciting prospect that careful classification of centrosome aberrations in human tumors might ultimately have diagnostic or prognostic value. Clearly, further work will be required before data obtained in cell culture models can be extrapolated to clinically relevant settings. Continued use of in vitro models for studying centrosome aberrations will be indispens- 
able for elucidating the molecular mechanisms underlying chromosome missegregation and/or the acquisition of invasive properties, but animal models and intravital imaging will increasingly become important for testing emerging models in vivo.

\section{ACKNOWLEDGMENTS}

We thank our laboratory members and colleagues in the centrosome field for helpful discussions. Work in the author's laboratory was supported by the University of Basel and a grant from the Swiss National Science Foundation (310030B-149641) to E.A.N.

\section{REFERENCES}

Arquint C, Nigg EA. 2014. STIL microcephaly mutations interfere with APC/C-mediated degradation and cause centriole amplification. Curr Biol 24: 351-360.

Arquint C, Nigg EA. 2016. The PLK4-STIL-SAS-6 module at the core of centriole duplication. Biochem Soc Trans 44: $1253-1263$.

Arquint C, Gabryjonczyk AM, Nigg EA. 2014. Centrosomes as signalling centres. Philos Trans R Soc Lond B Biol Sci 369: 20130464.

Arquint C, Gabryjonczyk AM, Imseng S, Böhm R, Sauer E, Hiller S, Nigg EA, Maier T. 2015. STIL binding to Polo-box 3 of PLK4 regulates centriole duplication. ELife 4: e07888.

Artym VV. 2016. Dense fibrillar collagen is a master activator of invadopodia. Mol Cell Oncol 3: e1035476.

Azimzadeh J, Marshall WF. 2010. Building the centriole. Curr Biol 20: R816-R825.

Azimzadeh J, Wong ML, Downhour DM, Sanchez Alvarado A, Marshall WF. 2012. Centrosome loss in the evolution of planarians. Science 335: 461-463.

Basto R, Lau J, Vinogradova T, Gardiol A, Woods CG, Khodjakov A, Raff JW. 2006. Flies without centrioles. Cell 125: 1375-1386.

Basto R, Brunk K, Vinadogrova T, Peel N, Franz A, Khodjakov A, Raff JW. 2008. Centrosome amplification can initiate tumorigenesis in flies. Cell 133: 1032-1042.

Bazzi H, Anderson KV. 2014. Acentriolar mitosis activates a p53-dependent apoptosis pathway in the mouse embryo. Proc Natl Acad Sci 111: E1491-E1500.

Bettencourt-Dias M, Rodrigues-Martins A, Carpenter L, Riparbelli M, Lehmann L, Gatt MK, Carmo N, Balloux F, Callaini G, Glover DM. 2005. SAK/PLK4 is required for centriole duplication and flagella development. Curr Biol 15: 2199-2207.

Bettencourt-Dias M, Hildebrandt F, Pellman D, Woods G, Godinho SA. 2011. Centrosomes and cilia in human disease. Trends Genet 27: 307-315.

Bornens M. 2012. The centrosome in cells and organisms. Science 335: 422-426.

Boveri T. 1914. Zur Frage der Entstehung maligner Tumoren. Gustav Fischer (Herausgeber), Jena.

Braun DA, Hildebrandt F. 2017. Ciliopathies. Cold Spring Harb Perspect Biol 9: a028191.

Casenghi M, Meraldi P, Weinhart U, Duncan PI, Korner R, Nigg EA. 2003. Polo-like kinase 1 regulates Nlp, a centrosome protein involved in microtubule nucleation. Dev Cell 5: 113-125.

Cattin CJ, Düggelin M, Martinez-Martin D, Gerber C, Muller DJ, Stewart MP. 2015. Mechanical control of mitotic progression in single animal cells. Proc Natl Acad Sci 112: 11258-11263.

Chan JY. 2011. A clinical overview of centrosome amplification in human cancers. Int J Biol Sci 7: 1122-1144.

Coelho PA, Bury L, Shahbazi MN, Liakath-Ali K, Tate PH, Wormald S, Hindley CJ, Huch M, Archer J, Skarnes WC, et al. 2015. Over-expression of Plk4 induces centrosome am- plification, loss of primary cilia and associated tissue hyperplasia in the mouse. Open Biol 5: 150209.

Conduit PT, Wainman A, Raff JW. 2015. Centrosome function and assembly in animal cells. Nat Rev Mol Cell Biol 16: 611624.

Di Martino J, Moreau V, Saltel F. 2015. Type I collagen fibrils: An inducer of invadosomes. Oncotarget 6: 28519-28520.

Fava LL, Schuler F, Sladky V, Haschka MD, Soratroi C, Eiterer L, Demetz E, Weiss G, Geley S, Nigg EA, et al. 2017. The PIDDosome activates p53 in response to supernumerary centrosomes. Genes Dev 31: 34-45.

Firat-Karalar EN, Stearns T. 2014. The centriole duplication cycle. Philos Trans R Soc Lon B Biol Sci 369: 20130460.

Fong CS, Mazo G, Das T, Goodman J, Kim M, O'Rourke BP, Izquierdo D, Tsou MF. 2016. 53BP1 and USP28 mediate p53dependent cell cycle arrest in response to centrosome loss and prolonged mitosis. ELife 5: e16270.

Fu J, Hagan IM, Glover DM. 2015. The centrosome and its duplication cycle. Cold Spring Harb Perspect Biol 7: a015800.

Ganem NJ, Storchova Z, Pellman D. 2007. Tetraploidy, aneuploidy and cancer. Curr Opin Genet Dev 17: 157-162.

Ganem NJ, Godinho SA, Pellman D. 2009. A mechanism linking extra centrosomes to chromosomal instability. Nature 460: 278-282.

Ganem NJ, Cornils H, Chiu SY, O'Rourke KP, Arnaud J, Yimlamai D, Thery M, Camargo FD, Pellman D. 2014. Cytokinesis failure triggers hippo tumor suppressor pathway activation. Cell 158: 833-848.

Ganier O, Schnerch D, Oertle P, Lim RYH, Plodinec M, Nigg EA. 2017. Structural centrosome aberrations promote non-cell-autonomous invasiveness. bioRxiv 216804; doi: 10.1101/216804.

Garcia G, Reiter JF. 2016. A primer on the mouse basal body. Cilia 5: 17 .

Gibson MC, Perrimon N. 2005. Extrusion and death of DPP/ BMP-compromised epithelial cells in the developing Drosophila wing. Science 307: 1785-1789.

Godinho SA, Pellman D. 2014. Causes and consequences of centrosome abnormalities in cancer. Philos Trans $R$ Soc Lond B Biol Sci 369: 20130467.

Godinho SA, Picone R, Burute M, Dagher R, Su Y, Leung CT, Polyak K, Brugge JS, Théry M, Pellman D. 2014. Oncogenelike induction of cellular invasion from centrosome amplification. Nature 510: 167-171.

Gönczy P. 2012. Towards a molecular architecture of centriole assembly. Nat Rev Mol Cell Biol 13: 425-435.

Gönczy P. 2015. Centrosomes and cancer: Revisiting a longstanding relationship. Nat Rev Cancer 15: 639-652.

Gu Y, Shea J, Slattum G, Firpo MA, Alexander M, Mulvihill SJ, Golubovskaya VM, Rosenblatt J. 2015. Defective apical extrusion signaling contributes to aggressive tumor hallmarks. ELife 4: e04069.

Gudipaty SA, Lindblom J, Loftus PD, Redd MJ, Edes K, Davey CF, Krishnegowda V, Rosenblatt J. 2017. Mechanical stretch triggers rapid epithelial cell division through Piezo1. Nature 543: 118-121.

Guichard P, Hachet V, Majubu N, Neves A, Demurtas D, Olieric N, Fluckiger I, Yamada A, Kihara K, Nishida Y, et al. 2013. Native architecture of the centriole proximal region reveals features underlying its 9-fold radial symmetry. Curr Biol 23: 1620-1628.

Guichard P, Hamel V, Le Guennec M, Banterle N, Iacovache I, Nemčíková V, Fl I, Goldie KN, Stahlberg H, Lévy D, et al. 2017. Cell-free reconstitution reveals centriole cartwheel assembly mechanisms. Nat Commun 8: 14813.

Guo HQ, Gao M, Ma J, Xiao T, Zhao LL, Gao Y, Pan QJ. 2007. Analysis of the cellular centrosome in fine-needle aspirations of the breast. Breast Cancer Res 9: R48.

Habedanck R, Stierhof YD, Wilkinson CJ, Nigg EA. 2005. The Polo kinase Plk4 functions in centriole duplication. Nat Cell Biol 7: 1140-1146.

Hinchcliffe EH, Miller FJ, Cham M, Khodjakov A, Sluder G. 2001. Requirement of a centrosomal activity for cell cycle progression through $\mathrm{G}_{1}$ into $\mathrm{S}$ phase. Science 291: 1547-1550. 
Hirono M. 2014. Cartwheel assembly. Philos Trans $R$ Soc Lond B Biol Sci 369: 20130458.

Holland AJ, Fachinetti D, Zhu Q, Bauer M, Verma IM, Nigg EA, Cleveland DW. 2012. The autoregulated instability of Pololike kinase 4 limits centrosome duplication to once per cell cycle. Genes Dev 26: 2684-2689.

Karsenti E, Vernos I. 2001. The mitotic spindle: A self-made machine. Science 294: 543-547.

Khodjakov A, Rieder CL. 2001. Centrosomes enhance the fidelity of cytokinesis in vertebrates and are required for cell cycle progression. J Cell Biol 153: 237-242.

Kitagawa D, Vakonakis I, Olieric N, Hilbert M, Keller D, Olieric V, Bortfeld M, Erat MC, Flückiger I, Gönczy P, et al. 2011. Structural basis of the 9-fold symmetry of centrioles. Cell 144: 364-375.

Kleylein-Sohn J, Westendorf J, Le Clech M, Habedanck R, Stierhof YD, Nigg EA. 2007. Plk4-induced centriole biogenesis in human cells. Dev Cell 13: 190-202.

Kratz AS, Bärenz F, Richter KT, Hoffmann I. 2015. Plk4-dependent phosphorylation of STIL is required for centriole duplication. Biol Open 4: 370-377.

Kwon M, Godinho SA, Chandhok NS, Ganem NJ, Azioune A, Thery M, Pellman D. 2008. Mechanisms to suppress multipolar divisions in cancer cells with extra centrosomes. Genes Dev 22: 2189-2203.

Lambrus BG, Holland AJ. 2017. A new mode of mitotic surveillance. Trends Cell Biol 27: 314-321.

Lambrus BG, Uetake Y, Clutario KM, Daggubati V, Snyder M, Sluder G, Holland AJ. 2015. p53 protects against genome instability following centriole duplication failure. J Cell Biol 210: 63-77.

Lambrus BG, Daggubati V, Uetake Y, Scott PM, Clutario KM, Sluder G, Holland AJ. 2016. A USP28-53BP1-p53-p21 signaling axis arrests growth after centrosome loss or prolonged mitosis. J Cell Biol 214: 143-153.

Levine MS, Bakker B, Boeckx B, Moyett J, Lu J, Vitre B, Spierings DC, Lansdorp PM, Cleveland DW, Lambrechts D, et al. 2017. Centrosome amplification is sufficient to promote spontaneous tumorigenesis in mammals. Dev Cell 40: 313-322.e315.

Lingle WL, Lutz WH, Ingle JN, Maihle NJ, Salisbury JL. 1998. Centrosome hypertrophy in human breast tumors: Implications for genomic stability and cell polarity. Proc Natl Acad Sci 95: 2950-2955.

Lingle WL, Barrett SL, Negron VC, D'Assoro AB, Boeneman K, Liu W, Whitehead CM, Reynolds C, Salisbury JL. 2002. Centrosome amplification drives chromosomal instability in breast tumor development. Proc Natl Acad Sci 99: 1978-1983.

Marshall TW, Lloyd IE, Delalande JM, Näthke I, Rosenblatt J. 2011. The tumor suppressor adenomatous polyposis coli controls the direction in which a cell extrudes from an epithelium. Mol Biol Cell 22: 3962-3970.

Meitinger F, Anzola JV, Kaulich M, Richardson A, Stender JD, Benner C, Glass CK, Dowdy SF, Desai A, Shiau AK, et al. 2016. 53BP1 and USP28 mediate $\mathrm{p} 53$ activation and $\mathrm{G}_{1}$ arrest after centrosome loss or extended mitotic duration. J Cell Biol 214: $155-166$.

Meraldi P, Honda R, Nigg EA. 2002. Aurora-A overexpression reveals tetraploidization as a major route to centrosome amplification in p53 $3^{-1-}$ cells. EMBO J 21: 483-492.

Moyer TC, Clutario KM, Lambrus BG, Daggubati V, Holland AJ. 2015. Binding of STIL to Plk4 activates kinase activity to promote centriole assembly. J Cell Biol 209: 863-878.

Nigg EA. 2002. Centrosome aberrations: Cause or consequence of cancer progression? Nat Rev Cancer 2: 815-825.

Nigg EA. 2007. Centrosome duplication: Of rules and licenses. Trends Cell Biol 17: 215-221.

Nigg EA, Holland AJ. 2018. Once and only once: Mechanisms of centriole duplication and their deregulation in disease. Nat Rev Mol Cell Biol (in press).

Nigg EA, Raff JW. 2009. Centrioles, centrosomes, and cilia in health and disease. Cell 139: 663-678.
Nigg EA, Stearns T. 2011. The centrosome cycle: Centriole biogenesis, duplication and inherent asymmetries. Nat Cell Biol 13: $1154-1160$.

Ohta M, Ashikawa T, Nozaki Y, Kozuka-Hata H, Goto H, Inagaki M, Oyama M, Kitagawa D. 2014. Direct interaction of Plk4 with STIL ensures formation of a single procentriole per parental centriole. Nat Commun 5: 5267.

Paz J, Luders J. 2017. Microtubule-organizing centers: Towards a minimal parts list. Trends Cell Biol. doi: 10.1016/j.tcb.2017. 10.005.

Pihan GA, Wallace J, Zhou Y, Doxsey SJ. 2003. Centrosome abnormalities and chromosome instability occur together in pre-invasive carcinomas. Cancer Res 63: 1398-1404.

Prosser SL, Pelletier L. 2017. Mitotic spindle assembly in animal cells: A fine balancing act. Nat Rev Mol Cell Biol 18: 187-201.

Quintyne NJ, Reing JE, Hoffelder DR, Gollin SM, Saunders WS. 2005. Spindle multipolarity is prevented by centrosomal clustering. Science 307: 127-129.

Rodriguez-Boulan E, Macara IG. 2014. Organization and execution of the epithelial polarity programme. Nat Rev Mol Cell Biol 15: 225-242.

Rodrigues-Martins A, Riparbelli M, Callaini G, Glover DM, Bettencourt-Dias M. 2007. Revisiting the role of the mother centriole in centriole biogenesis. Science 316: 1046-1050.

Rosenblatt J, Raff MC, Cramer LP. 2001. An epithelial cell destined for apoptosis signals its neighbors to extrude it by an actin- and myosin-dependent mechanism. Curr Biol 11: 1847-1857.

Salmon ED, Cimini D, Cameron LA, DeLuca JG. 2005. Merotelic kinetochores in mammalian tissue cells. Philos Trans $R$ Soc Lond B Biol Sci 360: 553-568.

Sánchez I, Dynlacht BD. 2016. Cilium assembly and disassembly. Nat Cell Biol 18: 711-717.

Schnerch D, Nigg EA. 2016. Structural centrosome aberrations favor proliferation by abrogating microtubule-dependent tissue integrity of breast epithelial mammospheres. Oncogene 35: 2711-2722.

Serçin Ö, Larsimont JC, Karambelas AE, Marthiens V, Moers V, Boeckx B, Le Mercier M, Lambrechts D, Basto R, Blanpain C. 2016. Transient PLK4 overexpression accelerates tumorigenesis in p53-deficient epidermis. Nat Cell Biol 18: 100-110.

Shao S, Liu R, Wang Y, Song Y, Zuo L, Xue L, Lu N, Hou N, Wang M, Yang X, et al. 2010. Centrosomal Nlp is an oncogenic protein that is gene-amplified in human tumors and causes spontaneous tumorigenesis in transgenic mice. $J$ Clin Invest 120: 498-507.

Silkworth WT, Nardi IK, Scholl LM, Cimini D. 2009. Multipolar spindle pole coalescence is a major source of kinetochore misattachment and chromosome mis-segregation in cancer cells. PLoS One 4: e6564.

Slattum GM, Rosenblatt J. 2014. Tumour cell invasion: An emerging role for basal epithelial cell extrusion. Nat Rev Cancer 14: 495-501.

Slattum G, McGee KM, Rosenblatt J. 2009. P115 RhoGEF and microtubules decide the direction apoptotic cells extrude from an epithelium. J Cell Biol 186: 693-702.

Slattum G, Gu Y, Sabbadini R, Rosenblatt J. 2014. Autophagy in oncogenic K-Ras promotes basal extrusion of epithelial cells by degrading S1P. Curr Biol 24: 19-28.

Szollosi D, Calarco P, Donahue RP. 1972. Absence of centrioles in the first and second meiotic spindles of mouse oocytes. $J$ Cell Sci 11: 521-541.

van Breugel M, Hirono M, Andreeva A, Yanagisawa HA, Yamaguchi S, Nakazawa Y, Morgner N, Petrovich M, Ebong IO, Robinson CV, et al. 2011. Structures of SAS-6 suggest its organization in centrioles. Science 331: 1196-1199.

Wong YL, Anzola JV, Davis RL, Yoon M, Motamedi A, Kroll A, Seo CP, Hsia JE, Kim SK, Mitchell JW, et al. 2015. Cell biology. Reversible centriole depletion with an inhibitor of Polo-like kinase 4. Science 348: 1155-1160.

Woodruff JB, Wueseke O, Hyman AA. 2014. Pericentriolar material structure and dynamics. Philos Trans R Soc Lond B Biol Sci 369: 20130459. 


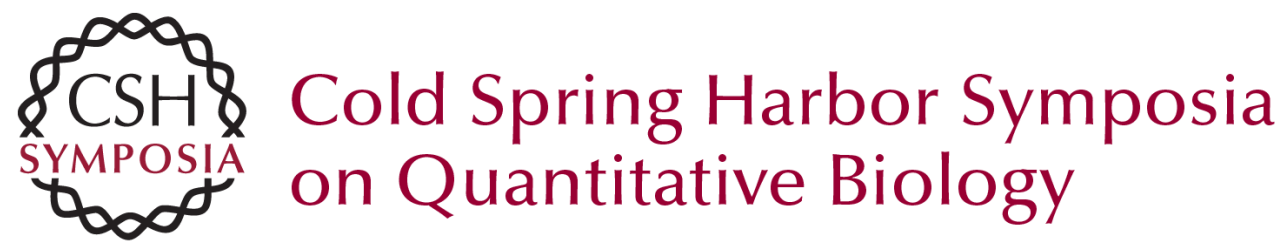

\section{Impact of Centrosome Aberrations on Chromosome Segregation and Tissue Architecture in Cancer}

Erich A. Nigg, Dominik Schnerch and Olivier Ganier

Cold Spring Harb Symp Quant Biol 2017 82: 137-144 originally published online April 2, 2018 Access the most recent version at doi:10.1101/sqb.2017.82.034421

References This article cites 84 articles, 31 of which can be accessed free at: http://symposium.cshlp.org/content/82/137.full.html\#ref-list-1

Creative This article is distributed under the terms of the

Commons http://creativecommons.org/licenses/by/4.0/, which permits unrestricted

License reuse and redistribution provided that the original author and source are credited.

Email Alerting Receive free email alerts when new articles cite this article - sign up in Service the box at the top right corner of the article or click here. 